\title{
Characterization of a novel mitochondrial DNA deletion in a patient with a variant of the Pearson marrow-pancreas syndrome
}

\author{
JMW van den Ouweland ${ }^{1,5}$, JBC de Klerk ${ }^{2}$, MP van de Corput ${ }^{1}$, RW Dirks ${ }^{1}, A K$ Raap $^{1}$, \\ HR Scholte ${ }^{3}$, JGM Huijmans ${ }^{4}$, LM 't Hart' ${ }^{1}$, GJ Bruining ${ }^{2}$ and JA Maassen ${ }^{1}$
}

\begin{abstract}
${ }^{1}$ Department of Molecular Cell Biology, Leiden University Medical Center, Leiden; ${ }^{2}$ Department of Paediatrics, Sophia Children's Hospital/A cademic Hospital Rotterdam, Erasmus University Rotterdam; ${ }^{3}$ D epartment of Biochemistry, Erasmus University Rotterdam; ${ }^{4}$ D epartment of Clinical Genetics, Academic Hospital Rotterdam, Erasmus University Rotterdam, The Netherlands
\end{abstract}

We have recently diagnosed a patient with anaemia, severe tubulopathy, and diabetes mellitus. As the clinical characteristics resembled Pearson marrow-pancreas syndrome, despite the absence of malfunctioning of the exocrine pancreas in this patient, we have performed DNA analysis to seek for deletions in mtDNA. DNA analysis showed a novel heteroplasmic deletion in mtDNA of 8034bp in length, with high proportions of deleted mtDNA in leukocytes, liver, kidney, and muscle. No deletion could be detected in mtDNA of leukocytes from her mother and young brother, indicating the sporadic occurrence of this deletion. During culture, skin fibroblasts exhibited a rapid decrease of heteroplasmy indicating a selection against the deletion in proliferating cells. We estimate that per cell division heteroplasmy levels decrease by $\mathbf{0 . 8 \%}$. By techniques of fluorescent in situ hybridisation (FISH) and mitochondria-mediated transformation of $\rho^{0}$ cells we could show inter- as well as intracellular variation in the distribution of deleted mtDNA in a cell population of cultured skin fibroblasts. Furthermore, we studied the mitochondrial translation capacity in cybrid cells containing various proportions of deleted mtDNA. This result revealed a sharp threshold, around $\mathbf{8 0 \%}$, in the proportion of deleted mtDNA, above which there was strong depression of overall mitochondrial translation, and below which there was complementation of the deleted mtDNA by the wild-type DNA. Moreover, catastrophic loss of mtDNA occurred in cybrid cells containing 80\% deleted mtDNA. European Journal of Human Genetics (2000) 8, 195-203.

Keywords: mitochondria; mutation; disease; diabetes

\section{Introduction}

Large-scale mitochondrial DNA (mtDNA) deletions have been associated with myopathies including chronic progressive ophthalmoplegia (CPEO) and Kearns-Sayre syndrome (KSS), ${ }^{1-3}$ as well as with non-muscular, multi-organ diseases such as Pearson's marrow-pancreas syndrome, ${ }^{4,5}$ and

Correspondence: Dr JA Maassen, Department of Molecular Cell Biology, Sylvius Laboratory, Leiden University Medical Center,

Wassenaarseweg 72, 2333 AL Leiden, The Netherlands. Tel:

+3171 5276127; Fax: +3171 5276284; E-mail: j.a.maassen@lumc.nl

${ }^{5}$ Current address: Isala Clinics, Clinical Chemistry Laboratory, PO Box 10500, 8000 GM Zwolle, The Netherlands

Received 30 March 1999; revised 6 October 1999; accepted 25 October 1999 maternally inherited adult-onset diabetes and deafness. ${ }^{6,7}$ MtDNA deletions differ in both size and location, but are confined to a region delineated by the $\mathrm{H}$-strand and L-strand origins of replication. The deletions include one or more tRNA genes and part or all of one or more protein reading frames, ${ }^{8,9}$ and often are flanked by perfect direct repeats 5-13bp in length. ${ }^{10}$ In most cases, mtDNA deletions are spontaneous events that occur either in the oocyte or during early stages of embryonic development. There appears to be no correlation between the size and/or location of the deletion and the clinical expression of the disease. The variable clinical presentation presumably depends on the distribution and the level of heteroplasmy (ie coexistence of 
mutant and wild-type mtDNA) in the body. A complex relationship between deleted/wild-type mtDNA ratio and phenotype has been reported which shows that when the level of heteroplasmy is below 55\%, wild-type mtDNA can complement the deleted mtDNA. However, when deleted mtDNAs predominate (ie heteroplasmy levels are greater than $65 \%$ ), they act dominantly and suppress translation of wild-type genomes. ${ }^{11-13}$ Pearson marrow-pancreas syndrome manifests as bone marrow failure and pancytopaenia, frequently associated with exocrine pancreatic insufficiency, hepatic and renal failure. Pearson's patients generally die young due to complications of bone marrow dysfunction or transfusions. ${ }^{14}$ Some Pearson patients spontaneously recover from their childhood sideroblastic anaemia, and ultimately progress to a KSS-like phenotype. 5,15

We have recently diagnosed a 3-year old patient with anaemia, severe tubulopathy, and diabetes mellitus, but no dysfunction of the exocrine pancreas. As the clinical characteristics resembled Pearson syndrome, we have performed DNA analysis to look for deletions in mtDNA. We here report on the identification of a novel heteroplasmic $8 \mathrm{~kb}$ deletion in mtDNA. In addition, we show by fluorescent in situ hybridisation (FISH) and mitochondria-mediated tran sformation of $\rho^{0}$ cells that inter- as well as intracellular variation in the distribution of deleted mtDNA exists in a cell population of cultured skin fibroblasts of this patient. Furthermore, we have analysed the threshold for expression of the biochemical phenotype in cybrid cells containing various proportions of deleted mtDNA by studying these cells for mitochondrial translation capacity.

\section{Materials and methods Patient}

The patient is the first child of non-related Caucasian parents. She presented at the age of 3 years with anaemia, severe Fanconi-like tubulopathy, lactic acidosis $(4.0 \mathrm{~mm}$ in plasma), electrolyte disturbances (potassium, sodium, magnesium, calcium, phosphate) and, eventually, diabetes. No dysfunction of the pancreas could be established. Enzyme investigations in a muscle biopsy revealed a carnitine deficiency, and deficiencies in all respiratory chain complexes, especially complex IV (COX-deficiency). She gradually developed glaucoma and ptosis of the eyes, hearing impairment and renal osteodystrophy. At the age of 5 years, growth hormone treatment $21 . \mathrm{E} . \mathrm{m}^{2} /$ day was started to induce protein synthesis and weight gain because her growth had stopped and her general condition deteriorated. At the age of 7 years, EPO-treatment was started, leading to improvement of the plasma haemoglobin level of $1 \mathrm{mmol} / \mathrm{l}$. After 2 years of GH-treatment, a new muscle biopsy revealed amelioration of all respiratory chain complexes (COX 23$63 \%)$. At the age of 8 years, her height is according to weight, being 2 SD below normal for age. The renal osteodystrophy responded well to treatment. The diabetes is well controlled.
She is fed by gastrostomy. Her mental development is normal, taking into account her visual and hearing impairment. She has a heal thy 4-year-old brother. Detailed description of the clinical characteristics, histological and biochemical examinations will be reported elsewhere (de Klerk, et al., in preparation).

\section{Cells, cell culture, and mitochondria-mediated transformation}

Peripheral blood and biopsies from liver, muscle, kidney and skin tissue were obtained at 3 and/or 5 years of age. Primary skin fibroblasts were grown on Dulbecco's modified Eagle medium containing $4.5 \mathrm{mg} / \mathrm{ml}$ of glucose and $110 \mu \mathrm{g} / \mathrm{ml}$ of pyruvate (DMEM) supplemented with $10 \%$ foetal bovine serum (FBS). The osteosarcoma cell line 143B. TK ${ }^{-}$(143B) was grown in DMEM supplemented with $100 \mu \mathrm{g} / \mathrm{ml}$ 5-bromodeoxyuridine (BrdU) and 5\% FBS. The cell line $\mathrm{B}^{\circ}-3, \mathrm{a}$ mtDNA-depleted derivative of $143 \mathrm{~B}$ cells, ${ }^{16}$ was grown in a medium of 143B cells supplemented with $50 \mu \mathrm{g} / \mathrm{ml}$ of uridine. Mitochondria-mediated transformation of $\mathrm{B}^{\circ}-3$ cells was carried out twice by fusion with enucleated fibroblasts as previously described. ${ }^{16,17}$

\section{DNA analysis}

Total genomic DNA was isolated from leukocytes, cultured skin fibroblasts, muscle, liver, and kidney biopsies, and cybrids by standard procedures. ${ }^{18}$ The ratio of mtDNA to nuclear DNA (mtDNA copy number), as well as the presence and proportion of deleted mtDNA, was determined by RFLP analysis. Five $\mu$ g of total DNA was digested with Pvu II (or Bam $\mathrm{HI})$ overnight at $37^{\circ} \mathrm{C}$, and fragments were resolved on a $0.8 \%$ agarose gel, followed by Southern blotting. ${ }^{18}$ The blot was hybridised with a mtDNA probe (a 6kb PCR fragment spanning the mtDNA region between nt 15788 and $5547^{19}$ or with a nuclear 18SrDNA probe. Hybridisation signals were quantified with a Phospholmager ${ }^{\mathrm{TM}}$ and visualised by autoradiography.

For rough mapping of the deletion break point, 1 $\mu \mathrm{g}$ of total DNA was submitted to PCR amplification using various sets of mtDNA primers with high mutual distance ( $\mathrm{gt} ; 3 \mathrm{~kb}$ ). Only in the case of a major deletion in mIDNA, did the primers become in close vicinity enabling a PCR fragment to be generated. The exact site of the deletion break point was determined by direct DNA sequencing of a PCR fragment spanning the deletion break point.

\section{Two-color fluorescence in situ hybridisation}

Two-color in situ hybridisation was performed as previously described. ${ }^{20}$

\section{Mitochondrial protein synthesis}

Approximately $5 \times 10^{5}$ of exponentially growing cells on culture plates were washed twice with phosphate-buffered saline (PBS), twice with methionine-free DMEM, and labelled with $\left[{ }^{35} \mathrm{~S}\right]-$ methionine $(1000 \mathrm{Ci} / \mathrm{mmol}, 100 \mu \mathrm{Ci} / \mathrm{ml})$ for $30 \mathrm{~min}$ 
in $1 \mathrm{ml}$ of methionine-free DMEM supplemented with $5 \%$ dialysed FBS at $37^{\circ} \mathrm{C}$. Emetine $(100 \mu \mathrm{g} / \mathrm{ml})$, an inhibitor of cytoplasmic protein synthesis, was added $15 \mathrm{~min}$ prior to labelling. After labelling, cells were washed twice with PBS, trypsinised, washed again twice with PBS, and finally lysed in $100 \mu$ l of $10 \mathrm{~mm}$ Tris- $\mathrm{HCl}$ pH7.5, $0.1 \%$ sodium dodecyl sulfate (SDS). Equal amounts of total cellular protein $(40 \mu \mathrm{g})$, as determined by the Bradford method, were loaded in each lane of a 15\% SDS-polyacrylamide gel. After electrophoresis, the gel was treated with Amplify (Amersham Pharmacia Biotech, Uppsala, Sweden), dried and exposed on Kodak $X$-Omat AR film. Mitochondrial translation products were assigned as described by Chomyn et al. ${ }^{17}$

\section{Western blot analysis}

Total cellular protein, dissolved in SDS-PAGE sample buffer (10\% glycerol, $5 \%$ mercaptoethanol, 3\% SDS, $0.1 \mathrm{M}$ Tris $\mathrm{PO}_{4}$, $\mathrm{pH} 6.8$, and $0.01 \%$ bromphenol blue) was separated on SDSPAGE gel and transferred to Immobilon (Millipore, Bedford, MA, USA). Subsequently, the membrane was blocked for $1 \mathrm{~h}$ in Tris-buffered saline, containing $0.25 \%$ Tween-20 (TBST) and $5 \%$ non-fat dried milk, and incubated simultaneously with monoclonal antibodies against COXI, COXII, and COXIV (Molecular Probes, Eugene, OR, USA) overnight in TBST at $4^{\circ} \mathrm{C}$. After washing with TBST, the membrane was incubated with anti-mouse IgG horseradish peroxidasecoupled second antibody for $\mathrm{lh}$ at room temperature in TBST. After washing, bound horseradish peroxidase conjugates were visualised by enhanced chemiluminescence (ECL, Amersham).

\section{Results \\ Characterisation of a mtDNA deletion}

Total DNA was isolated from various tissues and was digested by Pvull. This restriction endonuclease cleaves the mtDNA only once, outside the region where deletions generally are to be found. Subsequently, the mtDNA fragments were analysed by Southern blot using a $6 \mathrm{~kb}$ mtDNA fragment as the hybridisation probe. In the case of control DNA, a single $16.5 \mathrm{~kb}$ mtDNA fragment is generated, whereas in the case of the patient's DNA, two populations of mtDNA are present; one corresponding to a full-length molecule of mtDNA $(16.5 \mathrm{~kb})$ and the other corresponding to a smaller, deleted mtDNA molecule (8.5kb) (Figure 1a). In Tablel the proportion of deleted mtDNA in different tissues of this patient is shown. High proportions of deleted mtDNA (80 to $90 \%$ ) were found in all tissues examined, except for cultured skin fibroblasts (see below for explanation of relatively low level of $45 \%$ ). No deletion could be detected in leukocyte DNA from her mother and younger brother, even by PCR, indicating the sporadic occurrence of this deletion.

Biopsies from muscle, skin and liver were obtained twice within a 2 year period. No marked variation in the proportion of the deletion was noticed between the two time points.

Using PCR, we amplified selectively the region of the deleted genome spanning the deleted mtDNA and determined the exact position of the deletion break point by DNA sequencing. The deletion was $8034 \mathrm{bp}$ long, with the breakpoint on the left side at $\mathrm{np} 7934$ within the cytochrome $\mathrm{c}$ oxidasell (CO II) gene, and on the right side at position 15968 within the tRNA ${ }^{\text {Pro }}$ gene, thereby deleting the complete genes for ATPases6 and 8, COIII, ND3, ND4L, ND4, ND5, ND6,
A

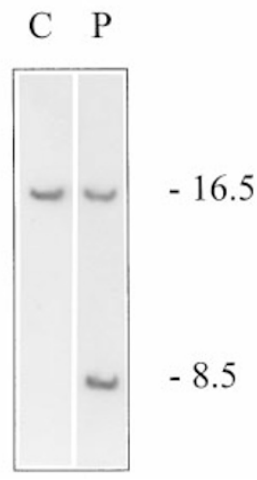

B

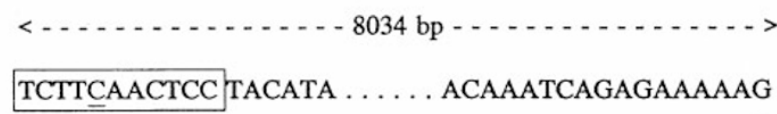

ACCGACTACGGCGGACTAA TCTTTAACTCCACCATTAGCACCCAAAGCTAAGAT

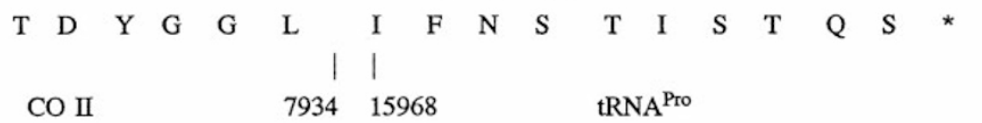

tRNA $^{\text {Pro }}$

Figure 1 Detection of mtDNA deletion in Pearson syndrome. a Southern blot analysis for the presence of a mtDNA deletion in total DNA isolated from a control subject $(C)$ and the Pearson patient (P). Five $\mu \mathrm{g}$ of total DNA was digested with Pvu II; fragments were resolved on a $0.8 \%$ agarose gel, transferred to Hybond $\mathrm{N}^{+}$, and probed with a $6 \mathrm{~kb}$ PCR fragment spanning the mtDNA region between nt 15788 and 5547. Size of the mtDNA fragments $(\mathrm{kb})$ is shown on the right. b Nucleotide sequence at the boundary of the deletion break point. The imperfect $11 \mathrm{bp}$ repeats are boxed, with the variant nucleotide underlined. The amino acid sequence (one-letter code) deduced from the COII/tRNA ${ }^{\text {Pro }}$ fusion gene is shown below the DNA sequence. COII, cytochrome $c$ oxidase subunit II. 
Table 1 Analysis of the proportion of deleted mtDNA in different tissues from a patient with Pearson syndrome

\begin{tabular}{lll}
\hline Tissue & & $\%$ deleted mtDNA \\
\hline Fibroblasts & t1 & 42 \\
Muscle & t2 & 51 \\
& t1 & 85 \\
Liver & t2 & 79 \\
& t1 & 90 \\
Kidney & t2 & 81 \\
Leukocytes & t1 & 86 \\
\hline
\end{tabular}

$\mathrm{t} 1=3$ years of age; $\mathrm{t} 2=5$ years of age.

cytb and 8tRNAs (Lys, Gly, Arg, His, Ser(AGY), Leu(CUN), Glu and Thr). The deletion was flanked by an imperfect $11 \mathrm{bp}$ repeat (Figure $1 b$ ). The fusion gene thus created encodes an mRNA that is out-of-frame in the tRNA $A^{\text {Pro }}$ portion of the predicted transcript, resulting in a premature termination codon 32 nucl eotides beyond the deletion breakpoint. Rather than encoding a CO II protein of 227 amino acids (deduced molecular weight of $25.5 \mathrm{kD}$ ), this mRNA, if translated, would encode a truncated protein 126 amino acids long (about 14kD).

\section{Disappearance of deleted mtDNA during culture}

Reanalysis of the proportion of deleted mtDNA in fibroblasts after several passages of culturing showed that the deleted mtDNA population was gradually lost, with levels of heteroplasmy going from $42 \%$ to $7 \%$. We estimate that during each passage the heteroplasmy level decreased by $0.8 \%$ over the first 35 days. This indicates that there appears to be a selection against the deletion in proliferating cells. It has been reported that supplementation of uridine, a nucleic acid precursor which allows growth of respiratory chain-deficient cells, to the culture medium maintains the presence of deleted mtDNA in cultured skin fibroblasts. ${ }^{21,22}$ Therefore, we reexamined heteroplasmy levels by culturing fibroblasts up to 75 days on medium containing two concentrations of glucose $(4.5 \mathrm{mg} / \mathrm{ml}$ or $1 \mathrm{mg} / \mathrm{ml})$, in the presence or absence of uridine. Figure 2 shows that, under the various culturing conditions, the proportion of deleted mtDNA decreased significantly. Heteroplasmy levels changed from $29 \%$ to barely detectable levels when cells were cultured in $1 \mathrm{mg} / \mathrm{ml}$ of glucose, both in the presence or absence of uridine, over a period of 75 days. When cultured in $4.5 \mathrm{mg} / \mathrm{ml}$ of glucose, the presence of uridine seemed to slightly protect the cells from a rapid decrease in heteroplasmy (Figure2).

\section{Mosaicism}

To examine whether there was an even or uneven distribution of normal and deleted mtDNA among individual cells from the same tissue, we performed fluorescent in situ hybridisation (FISH) on cultured skin fibroblasts. This technique enabled us to visualise wild-type and deleted mtDNA

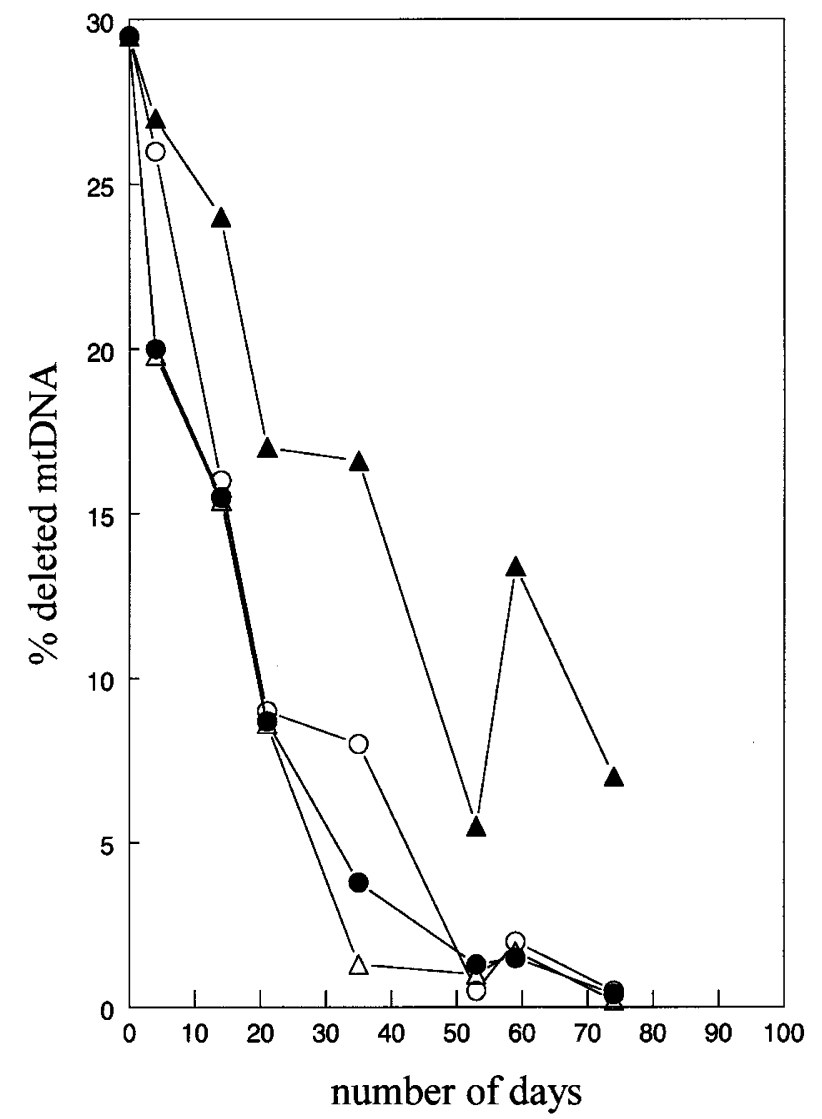

Figure 2 Graphic presentation of the changes in the proportion of deleted mtDNA with time in cultured skin fibroblasts from patient with Pearson syndrome. Cells were grown on Dulbecco's modified Eagle medium containing $4.5 \mathrm{mg} / \mathrm{ml}$ (triangles) or $1 \mathrm{mg} / \mathrm{ml}$ (circles) of glucose, in the presence (filled) or absence (open) of $50 \mu \mathrm{g} / \mathrm{ml}$ of uridine. The graph shows the result of one representative experiment.

simultaneously by using two probes, one common, biotinlabelled, probe (Cy3; red fluorescence), which hybridises to both wild-type and deleted mtDNA, and one deletion, digoxigenin-labelled, probe (FITC; green fluorescence), which hybridises to wild-type mtDNA only (Figure3a). Double excitation of both FITC and Cy3 results in yellow fluorescent staining of wild-type mtDNA, as a result of colocalisation of the two probes, and in red staining of deleted mtDNA, as a result of hybridisation of the common probe only. Heteroplasmy was observed at both the interand intracellular level in this cell population. A representative picture is shown in Figure $3 b$; here one cell had predominantly wild-type mtDNA (yellow staining), a second cell carried approximately equal amounts of wild-type and deleted mtDNA (orange staining), whereas a third cell carried predominantly deleted mtDNA (red staining). Among the red fluorescent signalling cells, a small amount of yellow staining 

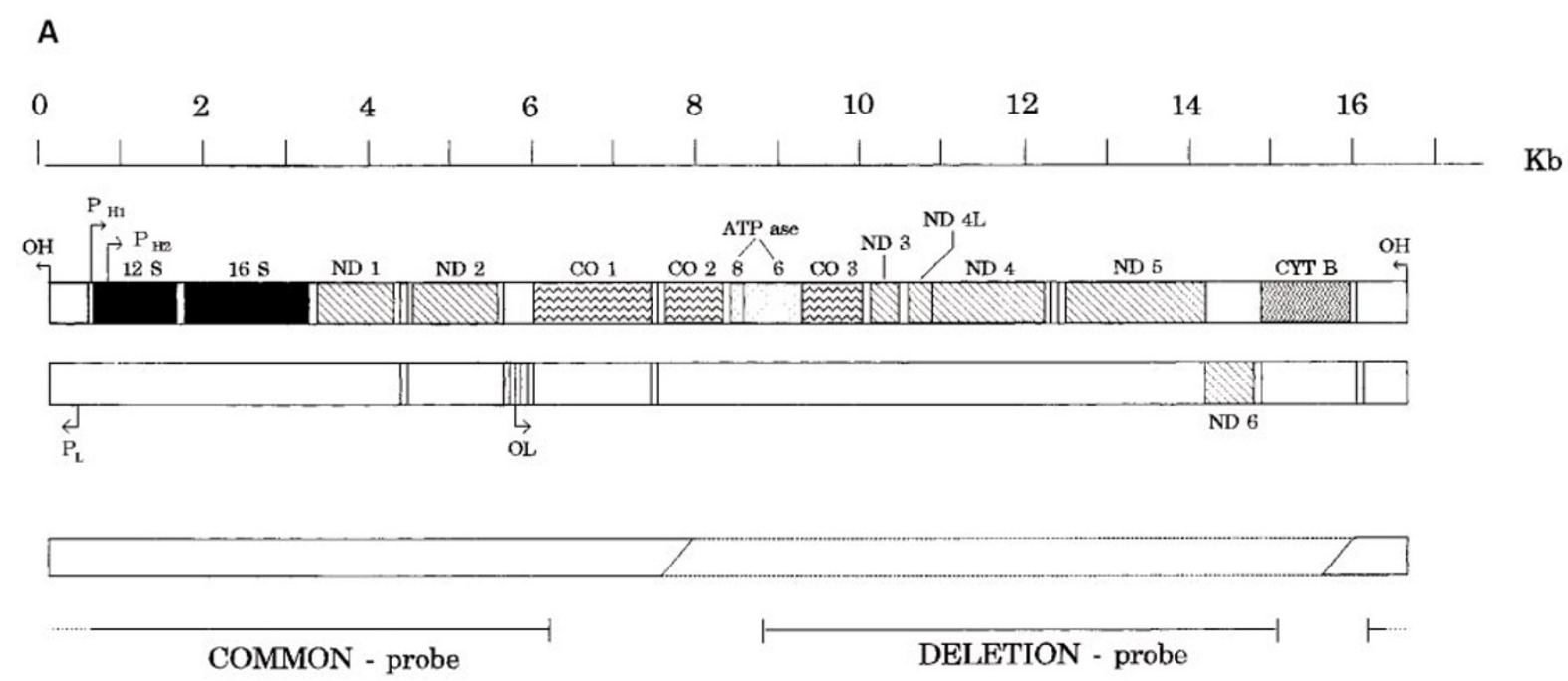

Patient

COMMON - probe

DELETION - probe

B

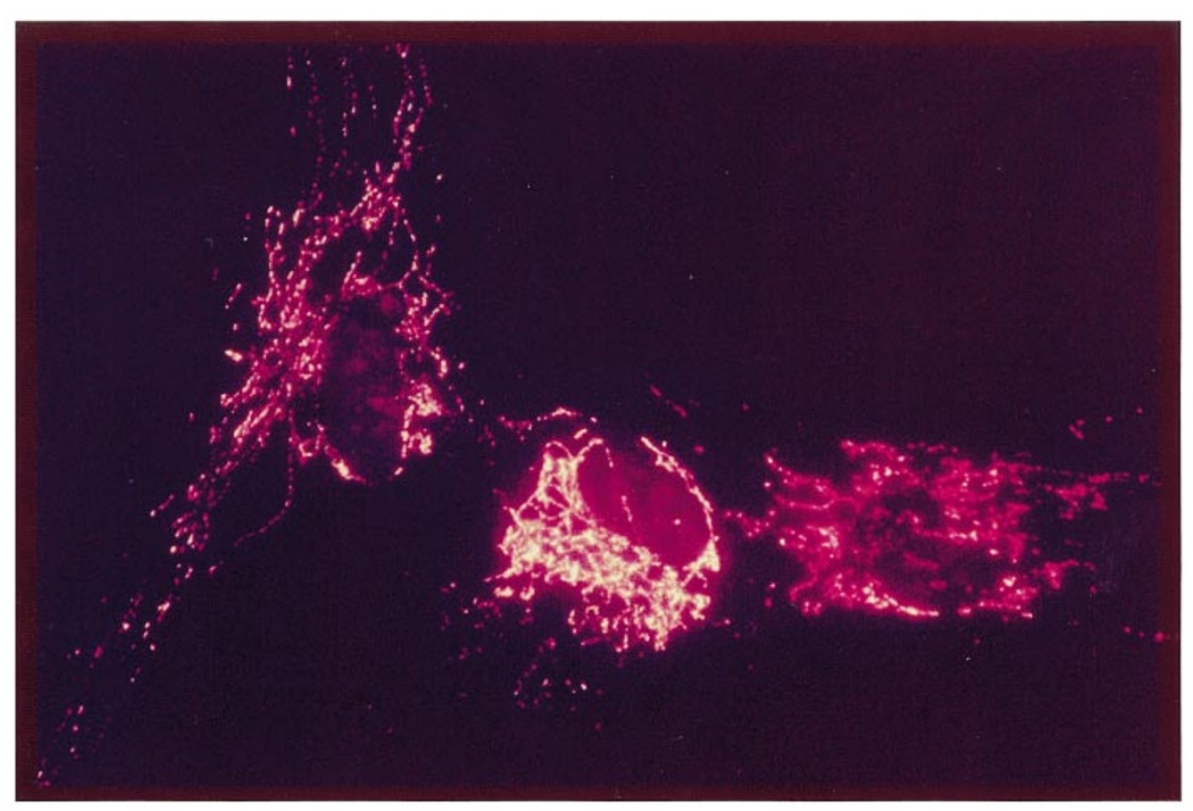

Figure 3 Visualization of inter- and intracellular mtDNA heteroplasmy in a cell population of cultured skin fibroblasts of a patient with Pearson syndrome by two-colour FISH: a schematic presentation of the mitochondrial genome showing the heavy and light strands, with the genes for the subunits of NADH-coenzyme Q reductase (ND), cytochrome c oxidase (CO), and ATP synthase (ATPase), cytochrome-b (cyt b), and for the $12 \mathrm{~S}$ and $16 \mathrm{~S}$ ribosomal RNAs. The tRNA genes are represented by small open boxes. Arrows indicate the origins of the heavy-strand $(\mathrm{OH})$ and light-strand $(\mathrm{OL})$ replication and the promoters for initiation of heavy-strand $\left(\mathrm{P}_{\mathrm{H}_{1}}\right.$ and $\left.\mathrm{P}_{\mathrm{H}_{2}}\right)$ and light-strand $\left(\mathrm{P}_{\mathrm{L}}\right)$ transcription. The mtDNA of the patient is represented by a bar in which the deleted 8034bp fragment is defined by dashed lines. The locations of the common 6347bp and deletion 6077bp probes are indicated. b Representative picture of cells hybridised with both common probe (Cy3; red fluorescence) and deleted probe (FITC; green fluorescence). Double excitation of both FITC and Cy3 results in yellow fluorescent staining as a result of colocalization of the two probes.

(due to simultaneously hybridisation of the green fluorescent deletion probe and the red fluorescent wild-type probe) was always present (Figure3b).
Threshold for phenotypic expression of deletion

Mitochondria from the fibroblast cell line were transferred into human cells lacking endogeneous mtDNA $\left(B \rho^{\circ}-3\right) .{ }^{16}$ 


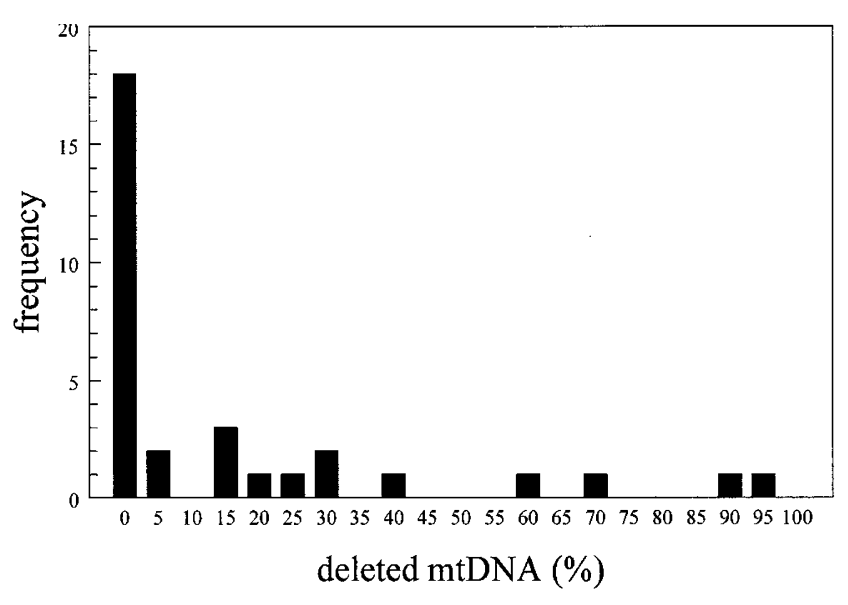

Figure 4 Frequency analysis of the proportion of deleted mtDNA in cybrid cells from patient with Pearson syndrome. The proportion of deleted mtDNA was determined by Pvu II digestion of total DNA, followed by Southern blotting using a $6 \mathrm{~kb}$ mtDNA fragment as a probe. Analysis was performed on 32 cybrids.

Independent cell clones (cybrids) were selected and grown for further analysis. The proportion of wild-type and deleted mtDNA was determined by Southern blot analysis (see Methods section). The degree of heteroplasmy in 32 cybrid clones ranged from 0 to $94 \%$ with more than half of the cybrids being homoplasmic wild-type (Figure4). The mean percentage of deleted mtDNA in the cybrids was $15 \%$. This value closely matched that found in the parental fibroblasts, which was $10 \%$ at the time of fusion. This observation agrees with a situation where the individual fibroblasts have a distribution of mtDNA genotypes which reflects that observed in the cybrids. During culture, no decrease in the proportion of deleted mtDNA was observed in the heteroplasmic cybrid cell lines.

We had major difficulty in culturing cybrid cells with $80 \%$ or more of deleted mtDNA over longer periods, despite the fact that our medium was supplemented with uridine. Re-examination of the levels of heteroplasmy in these particular clones by Southern blot analysis showed a complete loss of mtDNA signal, despite a normal nuclear DNA signal. Surprisingly, these cybrids had transformed into a $\rho^{\circ}$-like phenotype.

To prove that the $20 \%$ wild-type mtDNA was separated from the deleted mtDNA in the cybrid cell line containing $80 \%$ deleted mtDNA (as in theory these cybrid cells could contain $40 \%$ duplicated, $60 \%$ deleted and $0 \%$ wild-type mtDNA), a Bam HI digestion was performed. The Bam HI digestion revealed the presence of same amount $(20 \%$ of the total mtDNA signal) of the linear $16.5 \mathrm{~kb}$ fragment corresponding to wild-type mtDNA (result not shown), implying that this cybrid cell line still contained $20 \%$ wild-type mtDNA.

For functional studies, nine cybrids were selected with heteroplasmy levels ranging from 0 to $80 \%$ (Figure5a). Two of these (both with heteroplasmy levels of $80 \%$ ) were obtained from another, independent fusion experiment.

The effect of the deletion in mtDNA on mitochondrial protein synthesis was investigated by labelling cybrids with $\left.{ }^{35} \mathrm{~S}\right]$-methionine for $30 \mathrm{~min}$ in the presence of emetine, an inhibitor of cytoplasmic protein synthesis. As shown in Figure 5b, a marked overall decrease in the incorporation of $\left[{ }^{35} \mathrm{~S}\right]$-methionine into the mitochondrial-encoded polypeptides was observed in cybrids containing $80 \%$ of deleted mtDNA, whereas normal incorporation was found in cybrids containing up to $75 \%$ of deleted mtDNA, when compared with cybrids with $100 \%$ wild-type mtDNA. No CO II/tRNA ${ }^{\text {Pro }}$ fusion protein (expected molecular weight of $14 \mathrm{kD}$ ) could be detected in any of the cybrids. A possibility remains that this fusion protein becomes synthesised, but is prone to proteolytic degradation.

Steady-state levels of mtDNA-encoded subunitsI and II of cytochrome c oxidase (COXI and COX II, respectively) were determined by western blotting (Figure 5c). In 100\% wildtype cybrids, as well as in cybrids containing up to $75 \%$ of deleted mtDNA, both COXI and COXII protein could be detected. However, in the cybrids containing $80 \%$ of deleted mtDNA, no COI or COII signals were present. Levels of nuclear-encoded cytochrome c oxidase subunit IV (COX IV) were not different between all the cybrids.

\section{Discussion}

Deletions in mtDNA are consistently found in patients with Pearson syndrome, a combination of pancreatic, hepatic and renal insufficiency with pancytopenia. ${ }^{5}$ We have identified a hitherto unreported deletion of $8034 \mathrm{bp}$ length in the mtDNA of a patient with a variant of Pearson marrow-pancreas syndrome. This deletion is similar to what has previously been reported in patients with Pearson syndrome ${ }^{5}$ in a way that the deletion:

1) is confined to a region delineated by the $\mathrm{H}$-strand and L-strand origins of replication;

2) includes several tRNA genes and protein reading frames;

3) is flanked by an, al though imperfect, direct repeat in the normal mtDNA of $11 \mathrm{bp}$ in length;

4) has occurred as a spontaneous event; and

5) is present in high proportion in affected tissues.

An increase with time of the deleted mtDNA fraction in muscle was found in patients with KSS and this increase paralleled the progression of the disease. ${ }^{23}$ We have not seen any significant variation in the fraction of mtDNA deleted over a 2 year period of time in muscle or liver (see Table 1), which agrees with the clinical picture of the patient showing a non-progressive expression of the disease. 
A

$$
0010601623807580
$$

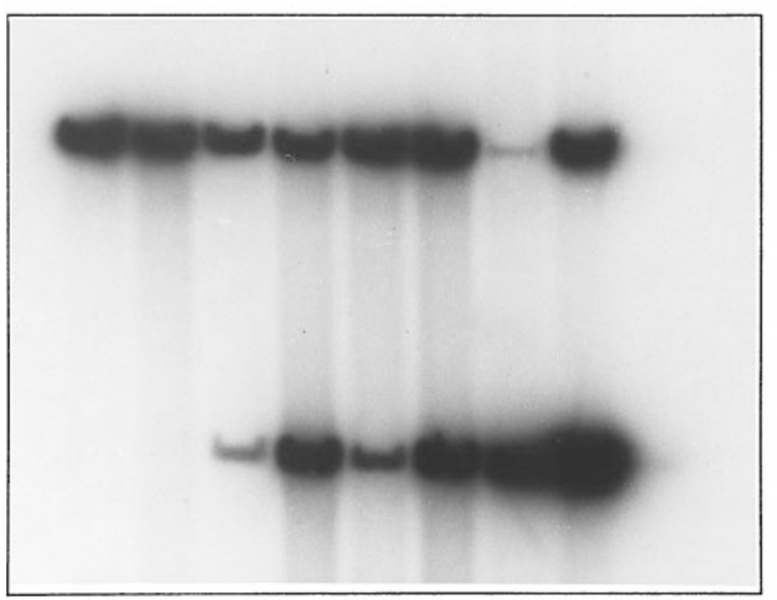

B

C

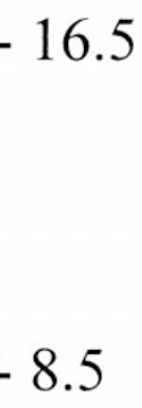

TPase 6

ND

ND 3

\section{$\begin{array}{llllll}0 & 23 & 60 & 75 & 80 & 80\end{array}$}

\section{$\begin{array}{lllllllll}0 & 0 & 10 & 75 & 80 & 80 & 60 & 23 & 16\end{array}$}

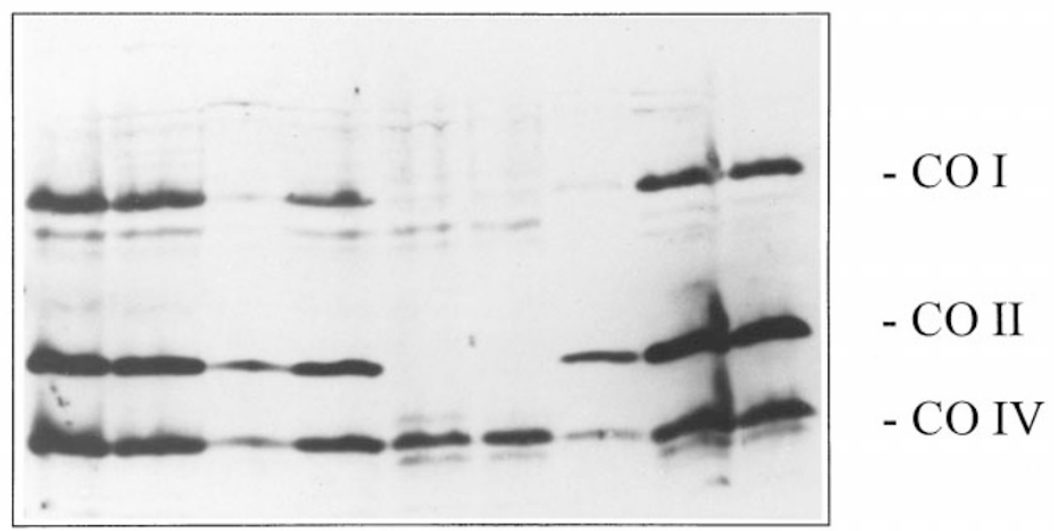

Figure 5 Mitochondrial protein synthesis in cybrid cell lines. a Southern blot analysis for the presence and proportion of mtDNA deletion in total DNA isolated from nine cybrid clones. The proportion of deleted mtDNA in each clone is indicated at the top of the lane. Size of the mtDNA fragments $(\mathrm{kb})$ is shown on the right. b Fluorogram of mitochondrial translation products labelled with $\left[{ }^{35} \mathrm{~S}\right]$ methionine after electrophoresis through a 15\% SDS-PAGE is shown for the different wild-type and deleted cybrid cell lines. After 30 min labelling in the presence of emetine, equal amounts of total cellular protein $(40 \mu \mathrm{g})$ were loaded in each lane. Bands were assigned according to Chomyn et al. ${ }^{17}$ c Steady-state levels of subunits of cytochrome coxidase. The figure shows a western blot of total cellular protein from different wild-type and deleted cybrid cell lines, incubated simultaneously with three monoclonal antibodies specific to COX subunitsI, II (mtDNA-encoded) and IV (nuclear DNA-encoded).

It was previously reported that supplementation of uridine in the culturing medium preserved the maintenance, or even resulted in the increase of deleted mtDNA in cultured fibroblasts. ${ }^{21,22}$ However, we noticed, even in the presence of uridine, a rapid loss of the deleted mtDNA in our culture of primary fibroblasts. It is not known whether the loss of deleted mtDNA occurs at the level of intracellular, as oppose to intercellular, selection in the cultured fibroblasts. In contrast, in our cybrid cells containing various proportions of deleted mtDNA, no marked change in heteroplasmy over time was observed when cultured in medium supplemented with uridine (we have not cultured cybrids in medium lacking uridine). Also, in a lymphoblast cell line derived from a patient with Pearson syndrome a heteroplasmy level of $60-70 \%$ deleted mtDNA was maintained over a 4-year period of continuous cell proliferation. ${ }^{24}$ Others have reported the preferential accumulation of deleted mtDNA over wild-type mtDNA in HeLa-cell derived cybrid cells. ${ }^{11}$ Altogether, these 
data indicate that segregation of deleted mtDNA may, or may not occur depending on the nuclear background of the cell containing deleted mtDNA. Also, in cybrid cells containing partially duplicated $m \mathrm{mDNA}^{25}$ or a specific point mutation in the mtDNA at np $3243,{ }^{26}$ uridine and the nuclear background were found as factors influencing the segregation of the mitochondrial phenotype.

From the mitochondrial translation studies in cybrid cells containing various proportions of deleted mtDNA, we conclude that when the level of heteroplasmy is below $80 \%$, wild-type mtDNA can complement the deleted mtDNA. Assuming that the deleted genome is transcribed, ${ }^{11,27}$ it is uncertain whether the fusion transcript becomes translated, as we did not observe the COII/tRNA ${ }^{\text {Pro }}$ fusion protein (expected molecular weight of $14 \mathrm{kD}$ ). Of course, we cannot exclude the possibility that the fusion protein becomes translated but is rapidly degraded. However, when deleted mtDNAs predominate (ie heteroplasmy levels are greater than $75 \%$ ), they act dominantly and suppress translation of wild-type genomes (Figure6) as has previously been reported. ${ }^{11-13}$ We had major difficulty in culturing cybrid cells with $80 \%$ of deleted mtDNA over longer time periods. $M$ tDNA gene content was easily lost in these cells, transforming them into a $\rho^{\circ}$-like phenotype. The presence of high levels of deleted mtDNA seems to perturb copy number control leading to catastrophic depletion of mtDNA, as has recently been reported in osteosarcoma cybrids containing partially duplicated mtDNA. ${ }^{25}$ The mechanism of mtDNA depletion in osteosarcoma cybrids remains unknown.

In a lymphoblast cell line containing $70 \%$ of deleted mtDNA, inhibition of mitochondrial protein synthesis by doxycycline resulted in the decline of the percentage of deleted mtDNA in culture. ${ }^{24}$ Upon removal of the doxycycline, the proportion of deleted mtDNA rapidly increased up to approximately the original level. The behaviour of deleted mtDNA before, during and after doxycycline treatment suggested that the percentage of mutant mtDNA is a balance between its preferential amplification and its phenotypic disadvantage. ${ }^{24}$ Despite the fact that mitochondrial protein

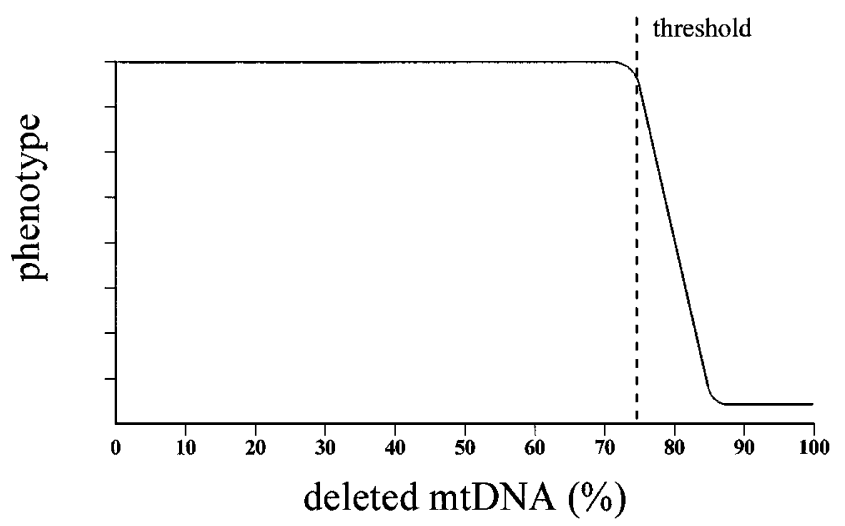

Figure 6 Graphic presentation of the threshold for expression of the biochemical phenotype in cells with deleted mtDNA. synthesis is clearly affected leading to metabolic disadvantage to cells, no selection against deleted mtDNA occurs in our cybrid cells containing $80 \%$ of deleted mtDNA. Rather, the percentage of $80 \%$ of deleted mtDNA is maintained, or might even be slowly increasing, ultimately leading to a disturbance in mtDNA copy number control by the osteosarcoma nuclear background through the operation of a yet unknown mechanism.

In conclusion, we have identified a novel $8 \mathrm{~kb}$ heteroplasmic mtDNA deletion in a patient with a variant of the Pearson marrow-pancreas syndrome. Cultured skin fibroblasts exhibited a rapid decrease of heteroplasmy indicating a selection against the deletion in proliferating cells. By techniques of fluorescent in situ hybridisation (FISH) and mitochondria-mediated transformation of $\rho^{0}$ cells we were able to show inter- as well as intracellular variation in the distribution of deleted mtDNA in a cell population of cultured skin fibroblasts. Finally, a sharp threshold, around $80 \%$, exists in the proportion of deleted mtDNA, above which there was strong depression of overall mitochondrial translation leading to a catastrophic loss of mtDNA, and below which there was complementation of the deleted mtDNA by the wild-type DNA.

\section{Acknowledgements}

This work was supported by grants from the Netherlands Diabetic Foundation and The Netherlands Organization for Scientific Research (NWO) through the foundation of Medical Research (GB-MW) to JM W vdO. We thank Ms S Lougheed for technical assistance.

\section{References}

1 Holt IJ, Harding AE, Morgan-Hughes JA: Deletions of muscle mitochondrial DNA in patients with mitochondrial myopathies. Nature 1988; 331: 717-719.

2 Moraes CT, DiMauro S, Zeviani $M$ et al: Mitochondrial DNA deletions in progressive external ophthalmoplegia and KearnsSayre syndrome. N Engl J Med 1989; 320: 1293-1299.

3 Zeviani M, Moraes CT, DiMauro S et al: Deletions of mitochondrial DNA in Kearns-Sayre syndrome. Neurology 1988; 38: 1339-1346.

4 Rötig A, Colonna M, Bonnefont JP et al: Mitochondrial DNA deletion in Pearson's marrow/pancreas syndrome. Lancet 1989; i: 902-903.

5 Rötig A, Bourgeron T, Chretien D, Rustin P, Munnich A: Spectrum of mitochondrial DNA rearrangements in the Pearson marrowpancreas syndrome. Hum Mol Genet 1995; 4: 1327-1330.

6 Dunbar DR, Moonie PA, Swingler RJ, Davidson D, Roberts R, Holt IJ: Maternally transmitted partial direct tandem duplication of mitochondrial DNA associated with diabetes mellitus. Hum Mol Genet 1993; 2: 1619-1624.

7 Ballinger SW, Shoffner JM, Gebhart S, Koontz DA, Wallace DC: Mitochondrial diabetes revisited. Nat Genet 1994; 7: 458-459.

8 Wallace DC, Shoffner JM, Trounce I et al: Mitochondrial DNA mutations in human degenerative diseases and aging. Biochim Biophys Acta 1995; 1271: 141-151.

9 Harding AE, Hammans SR: Deletions of the mitochondrial genome. J Inherit Metab Dis 1992; 15: 480-486.

10 Schon EA, Rizzuto R, Moraes CT, Nakase H, Zeviani M, DiMauro S: A direct repeat is a hotspot for large-scale deletion of human mitochondrial DNA. Science 1989; 244: 346-349. 
11 Hayashi J, Ohta S, Kikuchi A, Takemitsu M, Goto Y, Nonaka I: Introduction of disease-related mitochondrial DNA deletions into HeLa cells lacking mitochondrial DNA results in mitochondrial dysfunction. Proc Natl Acad Sci USA 1991; 88: 10614-10618.

12 Shoubridge EA, Karpati G, Hastings KE: Deletion mutants are functionally dominant over wild-type mitochondrial genomes in skeletal muscle fiber segments in mitochondrial disease. Cell 1990; 62: 43-49.

13 Moraes CT, Sciacco M, Ricci E et al: Phenotype-genotype correlations in skeletal muscle of patients with mtDNA deletions. Muscle Nerve 1995; 3: S150-S153.

14 Rötig A, Cormier V, Blanche S et al: Pearson's marrow-pancreas syndrome. A multisystem mitochondrial disorder in infancy. J Clin Invest 1990; 86: 1601-1608.

15 McShane MA, Hammans SR, Sweeney M et al: Pearson syndrome and mitochondrial encephalomyopathy in a patient with a deletion of mtDNA. Am J Hum Genet 1991; 48: 39-42.

16 Van den Ouweland JMW, Maechler P, Wollheim CB, Attardi G, Maassen JA: Functional and morphological abnormalities of mitochondria harbouring the tRNA ${ }^{\text {Leu(UUR) }}$ mutation in mitochondrial DNA derived from patients with maternally inherited diabetes and deafness (MIDD) and progressive kidney disease. Diabetologia 1999; 42: 485-492.

17 Chomyn A, Meola G, Bresolin N, Lai ST, Scarlato G, Attardi G: In vitro genetic transfer of protein synthesis and respiration defects to mitochondrial DNA-less cells with myopathy-patient mitochondria. Mol Cell Biol 1991; 11: 2236-2244.

18 Sambrook J, Fritsch EF, Maniatis T: Molecular Cloning: A Laboratory Manual, 2nd edn. Cold Spring Harbor Laboratory Press: Cold Spring Harbor, New York, 1989.

19 Anderson S, Bankier AT, Barrell BG et al: Sequence and organization of the human mitochondrial genome. Nature 1981; 290: 457-465.
20 Van de Corput MP, van den Ouweland JMW, Dirks RW et al: Detection of mitochondrial DNA deletions in human skin fibroblasts of patients with Pearson's syndrome by two-color fluorescence in situ hybridization. J Histochem Cytochem 1997; 45: 55-61.

21 Gerard B, Bourgeron T, Chretien D, Rötig A, Munnich A, Rustin P: Uridine preserves the expression of respiratory enzyme deficiencies in cultured fibroblasts. Eur J Pediatr 1993; 152: 270.

22 Bourgeron T, Chretien D, Rötig A, Munnich A, Rustin P: Fate and expression of the deleted mitochondrial DNA differ between human heteroplasmic skin fibroblast and Epstein-Barr virustransformed lymphocyte cultures. J Biol Chem 1993; 268: 19369-19376.

23 Larsson NG, Holme E, Kristiansson B, Oldfors A, Tulinius M: Progressive increase of the mutated mitochondrial DNA fraction in Kearns-Sayre syndrome. Pediatr Res 1990; 28: 131-136.

24 Spelbrink JN, Zwart R, Van Galen MJM, Van den Bogert C: Preferential amplification and phenotypic selection in a population of deleted and wild-type mitochondrial DNA in cultured cells. Curr Genet 1997; 32: 115-124.

25 Holt IJ, Dunbar DR, Jacobs HT: Behaviour of a population of partially duplicated mitochondrial DNA molecules in cell culture: segregation, maintenance and recombination dependent upon nuclear background. Hum Mol Genet 1997; 6: 1251-1260.

26 Dunbar DR, Moonie PA, Jacobs HT, Holt II: Different cellular backgrounds confer a marked advantage to either mutant or wildtype mitochondrial genomes. Proc Natl Acad Sci USA 1995; 92: 6562-6566.

27 Nakase H, Moraes CT, Rizzuto R, Lobes A, DiMauro S, Schon EA: Transcription and translation of deleted mitochondrial genomes in Kearns-Sayre syndrome: implications for pathogenesis. Am J Hum Genet 1990; 46: 418-427. 